\title{
ОСОБЕННОСТИ ВНЕСЕНИЯ В ЕГРН СВЕДЕНИЙ О РАНЕЕ УЧТЕННЫХ ОБЪЕКТАХ КАПИТАЛЬНОГО СТРОИТЕЛЬСТВА
}

\section{Яна Николаевна Бедарева}

Сибирский государственный университет геосистем и технологий, 630108, Россия, г. Новосибирск, ул. Плахотного, 10, обучающийся, тел. (913)470-42-46, e-mail: YanaBedareva232011@yandex.ru

\section{Наталья Олеговна Митрофанова}

Сибирский государственный университет геосистем и технологий, 630108, Россия, г. Новосибирск, ул. Плахотного, 10, кандидат технических наук, доцент кафедры кадастра и территориального планирования, тел. (383)344-31-73, e-mail: kadastr-204@yandex.ru

В статье рассматриваются особенности внесения сведений о ранее учтенных объектах недвижимости, в частности, объектов капитального строительства. В работе представлены результаты анализа оснований для отказа во внесении таких сведений.

Анализ показал, что наиболее частой причиной отказа во внесении сведений является отсутствие в представленных или поступивших документах данных, позволяющих считать такой объект недвижимости ранее учтенным. В работе предложены пути решения выявленных проблем.

Ключевые слова: единый государственный реестр недвижимости, ранее учтенные объекты недвижимости, объекты капитального строительства, государственный кадастровый учет

\section{FEATURES OF INTRODUCTION TO USRP OF INFORMATION ABOUT PREVIOUSLY REGISTERED OBJECTS OF CAPITAL CONSTRUCTION}

\section{Yana N. Bedareva}

Siberian State University of Geosystems and Technologies, 10, Plakhotnogo St., Novosibirsk, 630108, Russia, Student, phone: (913)740-42-46, e-mail: YanaBedareva232011@yandex.ru

\section{Natalia O. Mitrofanova}

Siberian State University of Geosystems and Technologies, 10, Plakhotnogo St., Novosibirsk, 630108, Russia, Ph. D., Associate Professor, Department of Cadastre and Territorial planning, phone: (383)344-31-73, e-mail: kadastr-204@yandex.ru

The article discusses the features of entering information about previously recorded real estate objects, in particular, capital construction objects. The paper presents the results of the analysis of the grounds for refusing to enter such information.

The analysis showed that the most common reason for refusing to enter information is the absence of data in the submitted or received documents that would allow such a property to be considered previously accounted for. The paper proposes ways of solving the identified problems.

Keywords: Unified State Register of Real Estate, previously registered real estate objects, capital construction objects, state cadastral registration

Говоря о государственном кадастровом учете, невозможно не упомянуть о технической инвентаризации, так как сведения о ранее учтенных объектах недвижимости в срок до 1 января 2013 года были переданы организациями тех- 
нической инвентаризации органу кадастрового учета [7].

Цель данной статьи заключается в том, чтобы выявить, особенности внесения в единый государственный реестр недвижимости (ЕГРН) сведений о ранее учтенных объектах капитального строительства.

Для достижения поставленной цели, необходимо решить следующие задачи:

- дать определение ранее учтенного объекта недвижимости;

- изучить особенности внесения в ЕГРН сведений о ранее учтенных объектах капитального строительства;

- провести анализ оснований для отказа во внесении сведений о ранее учтенном объекте в ЕГРН.

До вступления в силу ФЗ № 221 от 24.07.2007 N 221-Ф3 «О кадастровой деятельности» функции государственного кадастрового учета и технической инвентаризации объектов капитального строительства осуществляли органы технической инвентаризации (БТИ) [4]. Необходимость перехода от технического учета объектов недвижимости к кадастровому учету и создания государственного кадастра недвижимости обусловлена несколькими причинами:

- осуществление учета недвижимости различными органами;

- отсутствие единой системы сбора информации;

- необходимость определения кадастровой стоимости объектов недвижимости, для исчисления налога на недвижимость и налогового вычета.

С 1 января 2013 года государственный кадастровый учет осуществляется только в отношении тех объектов, которые не являются ранее учтенными объектами недвижимости.

Ранее учтенные объекты недвижимости - это объекты недвижимости, государственный или технический учет которых осуществлен органами технической инвентаризации. Также ранее учтенными объектами считаются объекты, права на которые зарегистрированы в ЕГРН и не прекращены, а также объекты которым были присвоены условные номера в порядке, установленном ФЗ от 21.04.1997 года № 122-Ф3, но технический или кадастровый учет которых не осуществлен [2].

Основания для внесения в ЕГРН сведений о ранее учтенных объектах недвижимости, согласно части 5 статьи 69 ФЗ от 13.07.2015 № 218-Ф3 представлены на рис. 1.

Для внесения сведений о ранее учтенных объектах недвижимости заинтересованное лицо подает заявление в орган регистрации через многофункциональный центр или другим способом, предусмотренном законодательством. К заявлению прикладываются документы, подтверждающие ранее осуществленный учет объекта недвижимости или государственную регистрацию права на него, либо документы устанавливающие или подтверждающие права на объект [3]. 


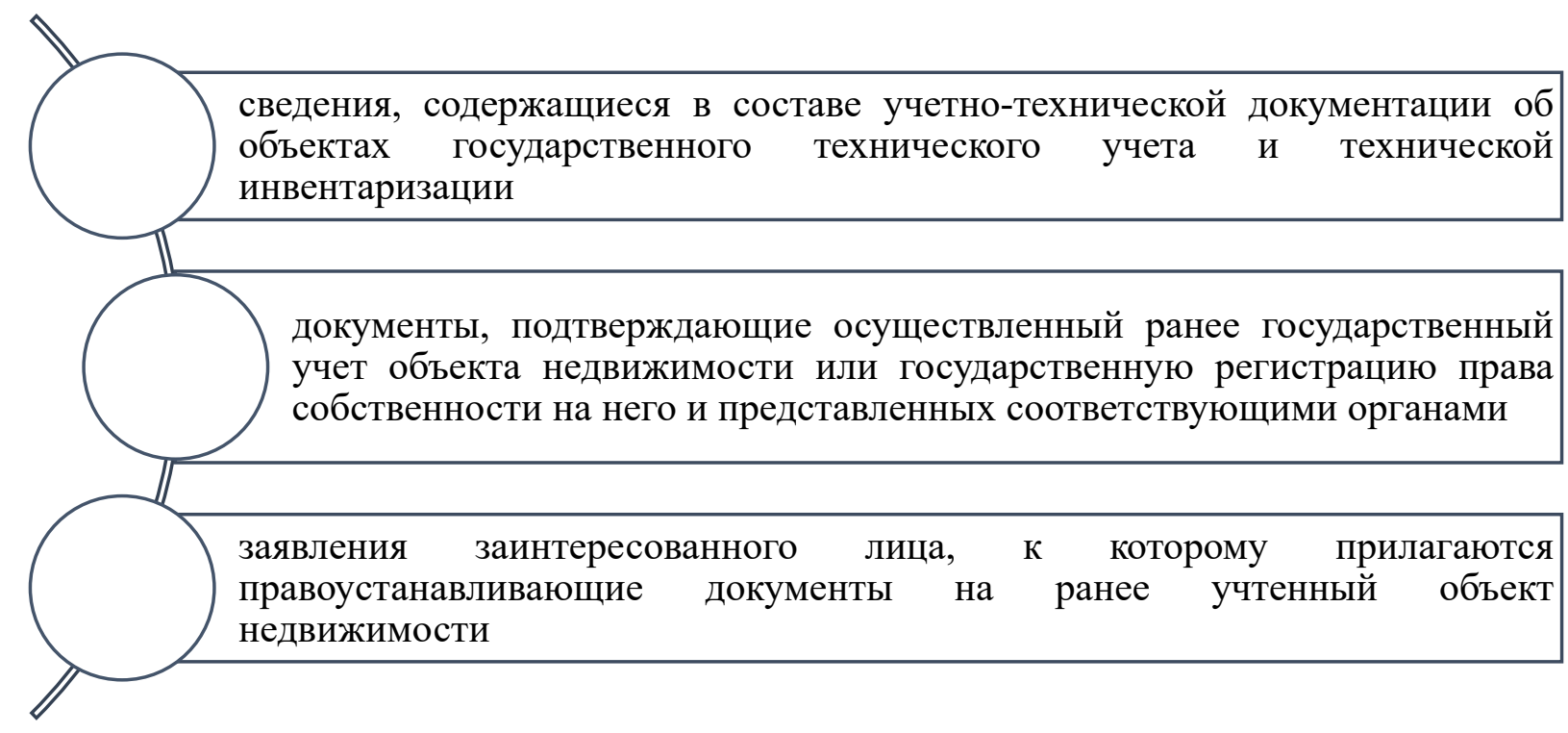

Рис. 1. Основания для внесения в ЕГРН сведений о ранее учтенных объектах недвижимости

Правоустанавливающим (правоудостоверяющим) документом на ранее учтенный объект недвижимости является: выписка из реестра муниципального/государственного имущества, справка о полной выплате паевого взноса до 31.02.1998, план приватизации, либо на объект имеется технический документ, составленный в соответствии с требованиями законодательства до 01.01.2013.

Распространенной ошибкой заявителей является предоставление документов для осуществления учетно-регистрационных действий по заявлению на одновременное внесение сведений и регистрацию прав. Порядок в данном случае предполагает предоставление документов последовательно: сначала на внесение сведений об объекте, а затем на регистрацию прав [1].

Основные причины отказа во внесении сведений о ранее учтенных объектах представлены на рис. 2.

Указанные обстоятельства приводят к приостановлению и последующему отказу во внесении сведений и регистрации прав на объект недвижимости, что влечет за собой излишние временные и материальные затраты [6].

Анализ выявленных основных ошибок показал, что наиболее типичными, и зависящими от результата запроса в орган технической инвентаризации причинами отказа, являются причины, содержащиеся в подп. 2 п. 8 ст. 69 Ф3 «О государственной регистрации недвижимости» от 13.07.2015 № 218-ФЗ: в представленных или поступивших документах отсутствуют сведения, позволяющие считать такой объект недвижимости ранее учтенным, отсутствуют сведения об основной характеристике объекта недвижимости, и (или) не поступил ответ на запрос органа регистрации прав. 


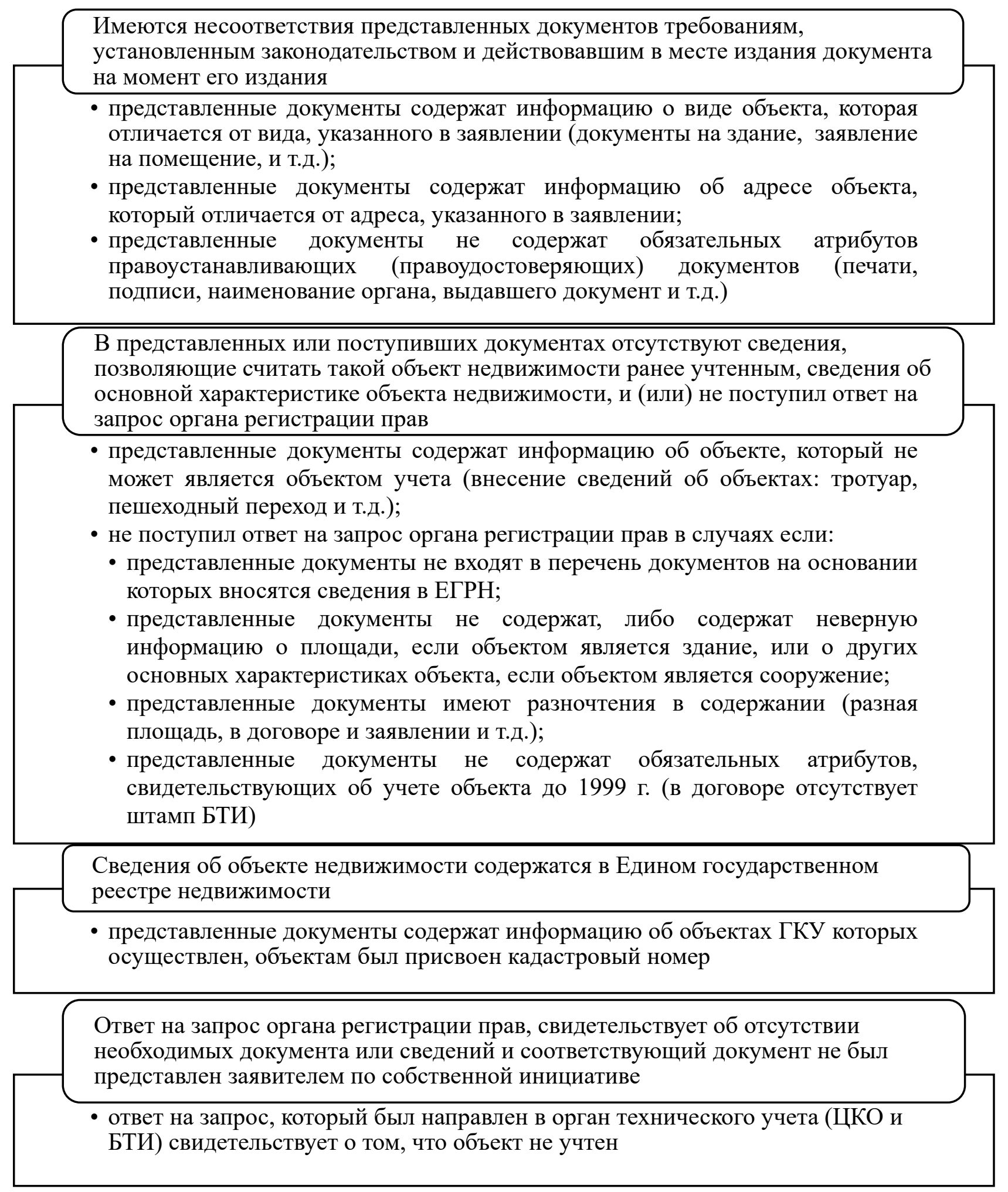

Рис. 2. Причины отказа во внесении сведений о ранее учтенных объектах

На практике данные обстоятельства являются причиной отказа наиболее часто, что обусловлено следующими факторами [5]:

- отсутствие до 2013 г. положений о постановке на кадастровый учет объектов капитального строительства (отсутствие единого регламента описания объектов); 
- отсутствие единых методов проверок сведений, которые были переданы БТИ в Росреестр (в связи с этим возникли разночтения между сведениями, содержащимися в технической документации и сведениях, которые были внесены в ЕГРН);

- короткий срок отработки заявления о внесении сведений о ранее учтенном объекте недвижимости (5 рабочих дней), за который в порядке межведомственного взаимодействия, ответ на запрос в «ЦКО и БТИ» не поступает в орган регистрации;

- отсутствие сведений об объектах в архивах органов технической инвентаризации «ЦКО и БТИ».

Также, рассматривая проблему ранее учтенных объектов капитального строительства, можно выделить следующие проблемы:

- заявительный порядок внесения сведений о ранее учтенных объектах недвижимости, из чего следует отсутствие в ЕГРН сведений о таких объектах, в полном объеме;

- заявительный порядок регистрации прав на ранее учтенные объекты, из чего следует отсутствие в ЕГРН сведений о правообладателях примерно 25 миллионов ранее учтенных объектов, права на которые возникли до вступления в силу Ф3 от 21.07.1997 г. № 122-Ф3 «О государственной регистрации прав на недвижимое имущество и сделок с ним».

Для решения данных проблем предлагается предусмотреть в законодательстве процедуру внесения в ЕГРН сведений о ранее учтенных объектах недвижимости и их правообладателях, наделив органы местного самоуправления и органы исполнительной власти городов федерального значения, полномочиями по выявлению таких объектов и их правообладателей; ввести обязательный порядок внесения сведений и регистрации прав на ранее учтенные объекты недвижимости капитального строительства [8].

Также эффективным методом пополнения ЕГРН сведениями о ранее учтенных объектах будут являться комплексные кадастровые работы.

Подводя итог, можно сделать следующие выводы:

- ранее учтенные объекты недвижимости - это объекты недвижимости, учет которых осуществлен органами технической инвентаризации и (или) объекты права, на которые зарегистрированы в ЕГРН и не прекращены;

- внесение сведений о ранее учтенных объектах и регистрация прав на них проходит в два этапа в отличие от сведений об иных объектах недвижимости, которые впервые вносятся в ЕГРН;

- наиболее часто причиной отказа во внесении сведений является отсутствие в представленных документах сведений, позволяющих считать объект недвижимости ранее учтенным, отсутствуют сведения об основной характеристике объекта недвижимости, и (или) не поступил ответ на запрос органа регистрации прав;

- заявительный характер внесения сведений о ранее учтенных объектах и их правообладателей приводит к низкой наполненности ЕГРН сведениями о таких объектах и об их правообладателях, недостаточной выплате налогов в местные и региональные бюджеты. 
Перечисленные факторы влияют на многие аспекты ведения ЕГРН и обусловливают вероятность наполнения ЕГРН недостоверной информацией, приводящей к искажению налогооблагаемой базы и ущемлению конституционных прав граждан Российской Федерации [8].

\section{БИБЛИОГРАФИЧЕСКИЙ СПИСОК}

1. Бадулина Е.В. Система государственной регистрации недвижимости в России: этапы становления и перспективы развития /Е.В. Бадулина // Имущественные отношения в Российской Федерации. - 2017. - № 7. - С. 617.

2. О государственной регистрации недвижимости [Электронный ресурс] : федер. закон от 13.07.2015 № 218-Ф3. - Доступ из справ.-правовой системы «КонсультантПлюс».

3. Клюшниченко, В.Н. Приостановления и отказы в проведении государственного кадастрового учета недвижимого имущества [Текст] / В.Н. Клюшниченко - Вестник СГУГиТ, Т. 23, № 4, Новосибирск, 2018, стр. 203-211.

4. Митрофанова, Н. О. Современное состояние государственного кадастрового учета объектов капитального строительства на территории Новосибирской области [Текст] / Н. О. Митрофанова // Интерэкспо ГЕО-Сибирь2013 : Междунар. науч. конгр. - Новосибирск : СГГА, 2013. - Т. 3. - С.137-142.

5. Алакоз В. В. Доклад о проблемах кадастра недвижимости и их преодолению [Электронный ресурс]. - Режим доступа : http://www.rachz.ru/gkn_probl.html.

6. Карпик, А.П. Совершенствование модели ведения государственного кадастра недвижимости в России [Текст] / А. П. Карпик, Д. Н. Ветошкин, О. П.Архипенко - Вестник СГГА, № 3 (23) 2013. - C. 53-60.

7. Жарников В. Б., Клюшниченко В. Н., Конева А. В. К вопросу об ошибках в сведениях Российского кадастра // Интерэкспо ГЕО-Сибирь-2017. XIII Междунар. науч. конгр. : Междунар. науч. конф. «Экономическое развитие Сибири и Дальнего Востока. Экономика природопользования, землеустройство, лесоустройство, управление недвижимостью» : Землеустройство, кадастр и мониторинг земель 209 сб. материалов в 2 т. (Новосибирск, 17-21 апреля 2017 г.). - Новосибирск : СГУГиТ, 2017. Т. 2. - С. 127-133.

8. Аврунев, Е. И. Проблемы кадастровой деятельности [Текст] / В.Н. Клюшниченко Геодезия и аэрофотосьемка №5/c. 2015г. Шехонин А. А., Домненко В. М., Гаврилина О. А. Методология проектирования оптических приборов : учеб. пособие. - СПб. : СПбГУ ИТМО, 2006. $-91 \mathrm{c}$.

(C) Я. Н. Бедарева, Н. О. Митрофанова, 2021 